\title{
The effect of segment length and gap distance on segmented rods penetrating into a steel target
}

\author{
X. W. Chen ${ }^{1,2}$ \& L. Lang ${ }^{2}$ \\ ${ }^{1}$ Institute of Systems Engineering, \\ China Academy of Engineering Physics, China \\ ${ }^{2}$ School of Civil Engineering, \\ Southwest University of Science and Technology, China
}

\begin{abstract}
Numerical simulations are conducted on the penetration of an $\mathrm{L} / \mathrm{D}=5$ long-rod and different ideal segment-rod into steel targets by ANSYS/LS-DYNA3D. The Lagrangian method and Johnson-Cook constitutive model are coupled in simulations. The comparative analysis indicates that the dominant contribution to the depth of penetration (DOP) of a segment-rod is due to the phase III nonsteady stage rather than the phase II quasi-steady penetration stage, which is dominant in long rod penetration. The effect of segment length and the gap distance on DOP are especially analyzed. The aspect ratio and gap distance of a segment do not affect DOP monotonically increasing or decreasing, instead there exists an optimal parameter region.

Keywords: numerical simulation, segmented rods, DOP, aspect ratio, gap distance, Johnson-Cook model.
\end{abstract}

\section{Introduction}

The theory for long rod penetration has been rapidly developed in recent decades, such as the one-dimensional Alekseevskii-Tate model $[1,2]$, which is widely used to depict the penetration behavior of a long rod. It indicates that the depth of penetration (DOP) of long-rod increases with its striking velocity and aspect ratio increasing. In the 1980s, Orphal and Miller [3] found that the penetration efficiency would increase if the projectile was comprised of a few of segments, which initiates the interest of investigation of penetration mechanism 
of segment-rod. Based on the experiments of segment-rod high-speed penetrating into steel targets, Sorensen et al. [4], Cuadros [5] and Wang et al. [6] respectively found that the penetration efficiency of segment-rod was higher than that of a single long-rod in a wide striking velocity range.

Chen et al. [7-10] investigated the penetration behaviors of long rod, ideal segment-rod and segment-rod with sleeve by numerical simulation. It indicates that the dominate contribution to DOP of segment-rod is due to the phase III non-steady stage rather than the phase II quasi-steady penetration stage, which is dominant in long-rod penetration. The inter-space of the segment-rod has a significant influence upon the DOP of segment-rod, while the sleeve only contributes to the increment of the diameter of crater.

In the present paper, we further discuss the effect of segment length and gap distance on DOP by numerical simulation. The analysis indicates that the aspect ratio and gap distance of segment do not affect DOP monotonically increasing or decreasing, instead there exists an optimal parameter region.

\section{Construction of numerical models}

The Johnson-Cook strength model and the accumulative damage failure model [11] are employed to depict the mechanical behavior of target and projectile. The Equation of State (EOS) adopts the Gruneisen equation, and the penetration process is considered as adiabatic process. Based on Ref. [12], Table 1 lists the parameters for alloy tungsten and steel target, respectively.

ANSYS/LS-DYNA3D is adopted to simulate the penetration behavior of targets and rods. Due to the structural and loading symmetry, only $1 / 4$ part of the rods and target are constructed. The outer surface of target is assumed nonreflectable to simulate infinite space. The unit system is cm-g-us.

Table 1: Material parameters of Johnson-Cook model.

\begin{tabular}{|c|c|c|c|c|c|c|c|}
\hline Material & $\begin{array}{c}\rho_{0} \\
\left(\mathrm{~g} / \mathrm{cm}^{3}\right)\end{array}$ & $\begin{array}{c}E \\
(\mathrm{Gpa})\end{array}$ & $\gamma$ & $\begin{array}{c}c_{p} \\
(\mathrm{~W} /(\mathrm{m} \cdot \mathrm{K}))\end{array}$ & $\begin{array}{c}T_{r} \\
(\mathrm{~K})\end{array}$ & $\begin{array}{c}T_{m} \\
(\mathrm{~K})\end{array}$ & $\begin{array}{c}\dot{\varepsilon}_{0} \\
\left(\mathrm{~s}^{-1}\right)\end{array}$ \\
\hline Alloy tungsten & 17.6 & 310 & 0.3 & 134 & 300 & 1752 & 1 \\
\hline Steel & 7.85 & 200 & 0.29 & 477 & 300 & 1793 & 1 \\
\hline Material & $\begin{array}{c}A \\
(\mathrm{Mpa})\end{array}$ & $\begin{array}{c}B \\
(\mathrm{Mpa})\end{array}$ & $n$ & $C$ & $m$ & $S_{1}$ & $\begin{array}{c}C_{0} \\
\left(\mathrm{~m}^{-\mathrm{s}^{-1}}\right)\end{array}$ \\
\hline Alloy tungsten & 1506 & 177 & 0.12 & 0.016 & 1.00 & 1.44 & 3850 \\
\hline Steel & 792 & 510 & 0.26 & 0.014 & 1.03 & 1.33 & 4578 \\
\hline Material & $\gamma_{0}$ & $D_{1}$ & $D_{2}$ & $D_{3}$ & $D_{4}$ & $D_{5}$ & $a$ \\
\hline Alloy tungsten & 1.58 & 0.16 & 3.13 & -2.04 & 0.007 & 0.37 & \\
\hline Steel & 1.67 & 0.05 & 3.44 & -2.12 & 0.002 & 0.61 & 0.47 \\
\hline
\end{tabular}


(a) Long rod
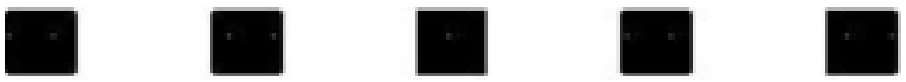

(b) segment-rod

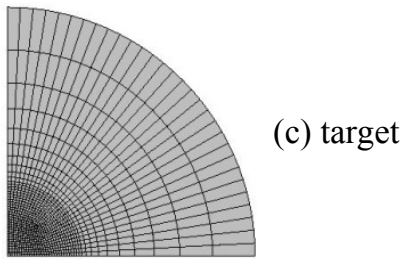

Figure 1: Schematics of the three types of rods and the target used in simulation.

The FEA models for targets and rods are shown in Fig. 1. There are two kinds of rods made of tungsten alloy with diameter $7 \mathrm{~mm}$. The first is long-rod with aspect ratio (L/D) as 5 and total length as $35 \mathrm{~mm}$. The second is ideal segmentrod and the total length of segments is still $35 \mathrm{~mm}$ but the segment lengths are $\mathrm{L}=3.5 \mathrm{~mm}, 5 \mathrm{~mm}, 7 \mathrm{~mm}, 11.7 \mathrm{~mm}$ and $17.5 \mathrm{~mm}$, respectively. That means, the amount of segments is $10,7,5,3$ and 2, respectively. Meanwhile, the gap distance between segments are $S=0 \mathrm{~mm}, 3.5 \mathrm{~mm}, 5 \mathrm{~mm}, 7 \mathrm{~mm}, 10.5 \mathrm{~mm}, 14 \mathrm{~mm}$ and $21 \mathrm{~mm}$, respectively. It should be mentioned that the mass of ideal segmentrod is the same as that of the long-rod.

The target is made of RHA steel and its dimension is $\Phi 70 \mathrm{~mm} \times 100 \mathrm{~mm}$. The target and projectile are meshed with mapping meshing. The element type is SOLID164 of hexahedron shape with eight nodes. The element size is $0.3 \mathrm{~mm} \times 0.3 \mathrm{~mm} \times 0.3 \mathrm{~mm}$ for projectile and the center of target. It increases gradually from target centre to reduce the calculation time. The contact algorithm is 3D SURFACE TO SURFACE ERODING CONTACT.

\section{Validations of numerical models}

\subsection{Long rod penetration}

Orphal [13] suggested that the long rod penetration could be divided into four stages. Phase I is initial striking phase. In this stage, the depth of initial crater is only a few times of rod diameter. Phase II is quasi-steady penetration stage. The target and projectile deforms as semi-fluid and then the strength of target and projectile should be considered to describe the penetration behavior of rod. In this stage, Alekseevskii-Tate model is applicable. After the projectile is almost eroded completely, Phase III initiates. It may include secondary penetration and after-flow penetration. The secondary penetration is induced by the debris of rod, 
and it occurs when the rod density is larger than that of target and the striking velocity is comparatively high. The after-flow penetration means that there is kinetic energy stored in the crater area and it will continue to increase the DOP. The final Phase IV is the elastic recovery of target and it is usually neglected.

The penetration process of long rod at $v_{0}=2.0 \mathrm{~km} / \mathrm{s}$ and its distribution of Von-Mises stress are shown in Fig. 2. The time histories of rod-target interface pressure and velocities of rod head and tail are respectively shown in Figs. 3 and 4. It indicates that the numerical results are in good agreement with Orphal's suggestions, i.e., Phase II dominates the penetration process of long-rod.

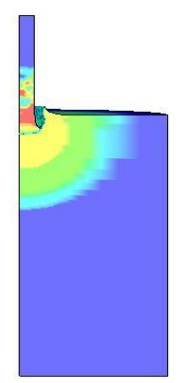

(a)

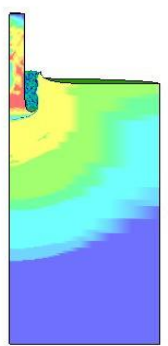

(b)

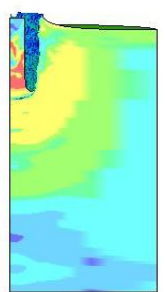

(c)

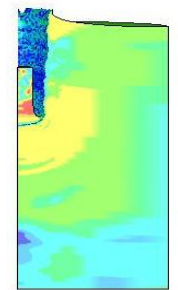

(d)

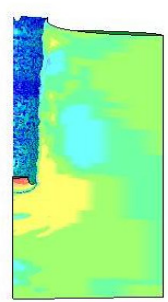

(e)

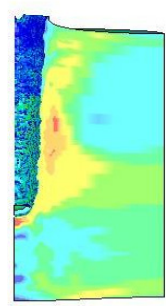

(f)

Figure 2: Contours of Von Mises stress of long rod and target during penetration:

(a) $t=4.2 \mu \mathrm{s}$;

(b) $t=8.1 \mu \mathrm{s}$;

(c) $t=16.2 \mu s$;

(d) $t=23.4 \mu s$; (e) $t=39 \mu s$; (f) $t=80 \mu s$.

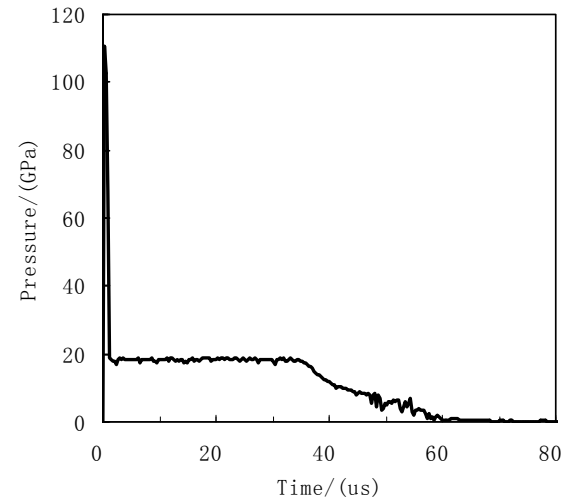

Figure 3: History of rod-target interface pressure for a long-rod penetration at $v_{0}=2.0 \mathrm{~km} / \mathrm{s}$.

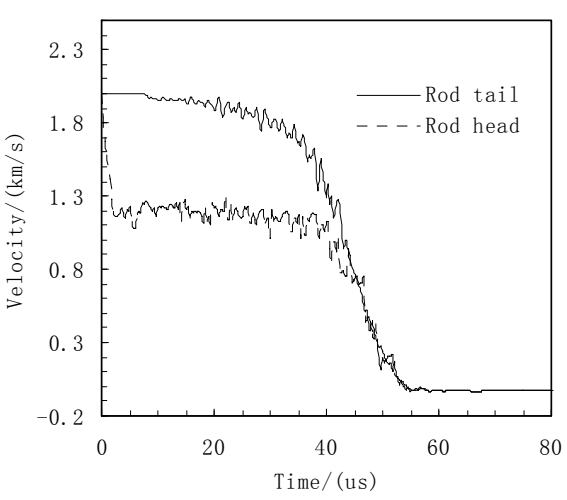

Figure 4: Velocity history for a long-rod penetration at $v_{0}=2.0 \mathrm{~m} / \mathrm{s}$. 


\subsection{Ideal segment-rod penetration}

Fig. 5 shows the penetration behavior of ideal segment-rod at $v_{0}=2.0 \mathrm{~km} / \mathrm{s}$ and its Von-Mises stress distribution. Figs. 6 and 7 respectively show the time histories of rod-target interface pressure and velocities of segment head and tail. The penetration behavior of ideal segment-rod could be described through analyzing penetration behavior of single one segment with aspect ratio 1 .

There are essential difference between the penetration of long-rod and shortrod (here is segment). As shown in Figs. 5 to 7, the segment is not able to form quasi-steady penetration but shows behavior similar to Phase III. Further analysis indicates that the stress wave does not reach the segment tail till instant $1.5 \mu \mathrm{s}$ and the velocity of segment tail is still $2.0 \mathrm{~km} / \mathrm{s}$ at this instant. Since the length of segment is short, the stress wave quickly reaches the segment tail afterwards and then the velocities of segment head and tail are almost same. At $\mathrm{t}=6.6 \mu \mathrm{s}$, only the

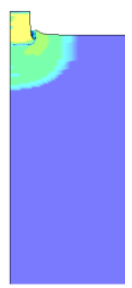

(a)

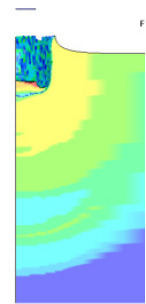

(b)

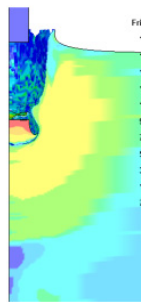

(c)

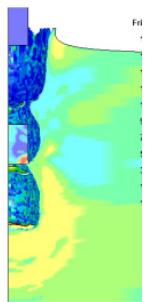

(d)

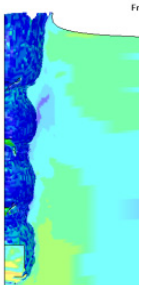

(e)

Figure 5: Contours of Von Mises stress of ideal segment-rod penetration: (a) $t=1.5 \mu \mathrm{s}$; (b) $t=6.6 \mu \mathrm{s}$; (c) $t=20.1 \mu \mathrm{s}$; (d) $t=41.4 \mu \mathrm{s}$; (e) $t=63.9 \mu \mathrm{s}$.

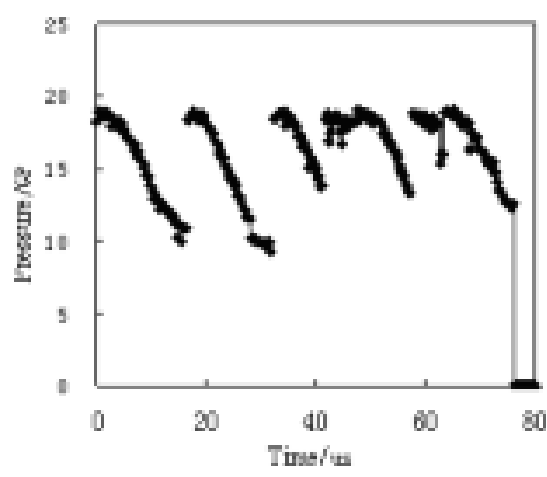

Figure 6: Time history of rodtarget interface pressure for an ideal segment-rod penetration.

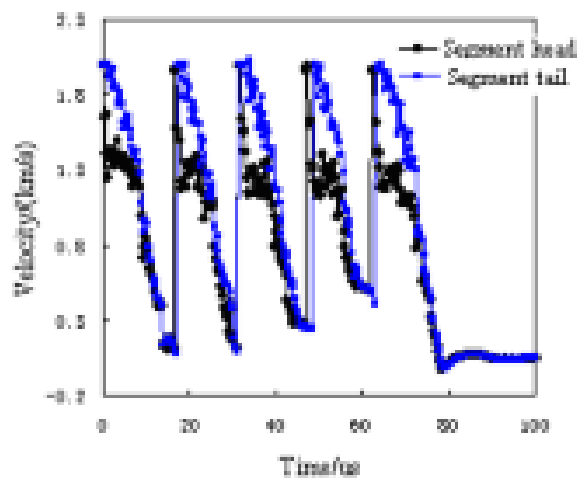

Figure 7: Velocity history for an ideal segment-rod penetration. 
debris of segment continues to penetrate the target. The DOP gradually increases until the segment is completely eroded at time $16.5 \mu \mathrm{s}$.

The rod-target interface pressure decreases monotonously from $18 \mathrm{GPa}$ to $10 \mathrm{GPa}$ (Fig. 6). It indicates the major contribution to penetration of ideal segment-rod is Phase III rather than Phase II of quasi-steady penetration. The velocity of each segment decreases rapidly and the time histories for each segment are almost parallel to each other (Fig. 7).

\subsection{Comparative analysis of long rod and ideal segment-rod}

Fig. 8 shows the crater profiles for long rod and ideal segment-rod, respectively. The crater diameter of long rod is close to its diameter, and the path is straight and its bottom is conical. The crater profile of ideal segment-rod is similar to candied gourd and its diameter decreases with DOP increasing. In general, the crater diameter of ideal segment-rod is larger than that of long rod.

Fig. 9 shows the time histories of kinetic energy for targets, long rod and ideal segment-rod. The initial kinetic energy for the alloy tungsten rod is the same and the kinetic energy of target is small. However, the times to consume the kinetic energy for different rods are different. The time for ideal segment-rod is

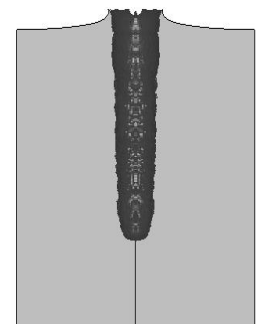

(a)

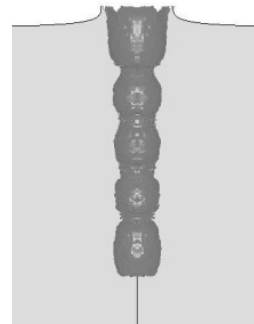

(b)

Figure 8: Crater profiles of long rod and segment-rod penetrating into steel target: (a) Long rod; (b) Ideal segment-rod.

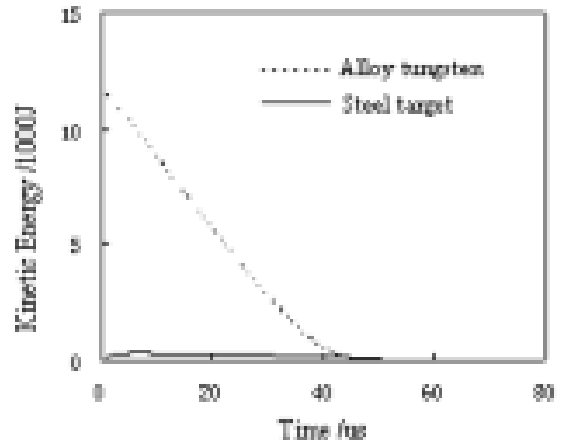

(a)

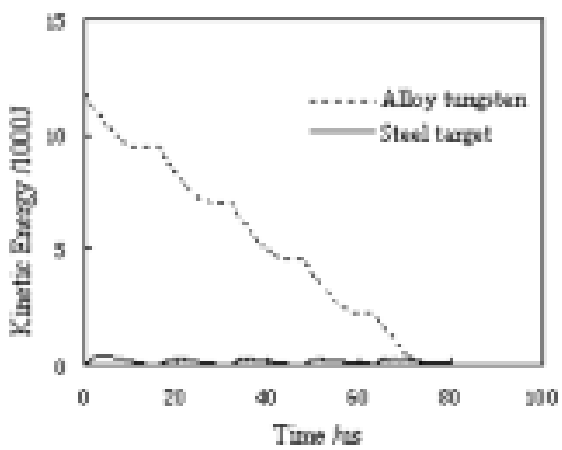

(b)

Figure 9: History of the kinetic energy of different rods and the targets: (a) Long rod; (b) Ideal segment-rod. 
obviously larger than that of long rod, for the inter-space between two segments increases the total length of rod and the secondary penetration and afterwards fluid penetration occur during this period.

\section{Penetration of ideal segment-rod with different segment aspect ratio}

In this section, we simulated the ideal segment-rod penetration with different segment lengths at $v_{0}=2.0 \mathrm{~km} / \mathrm{s}$. The gap distance of segments is $\mathrm{S}=14 \mathrm{~mm}$ but the segment lengths are $\mathrm{L}=3.5 \mathrm{~mm}, 5 \mathrm{~mm}, 7 \mathrm{~mm}, 11.7 \mathrm{~mm}$ and $17.5 \mathrm{~mm}$, respectively.

Fig. 10 shows the relationship between DOP and time for different segment lengths, and Fig. 11 shows the variation of DOP with segment length. The Von Mise stress distribution in targets regarding different segment aspect ratios are shown in Fig. 12. Obviously, the segment-rods with shorter segment length, e.g.,

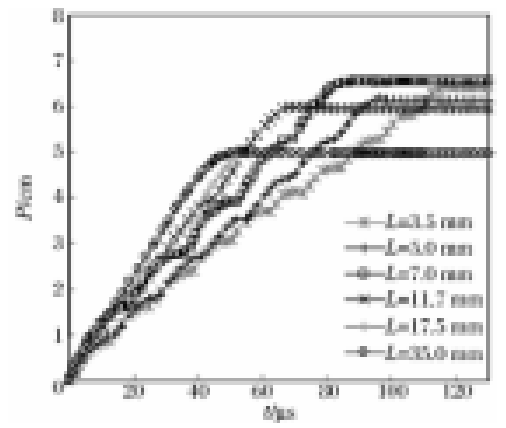

Figure 10: DOP vs. time for various segmented rods.

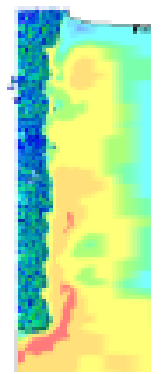

(a)

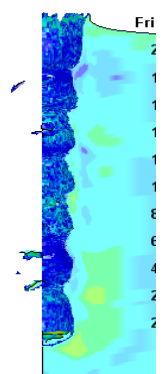

(b)

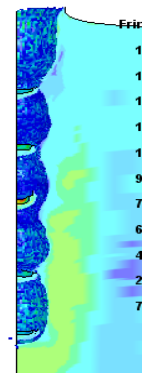

(c)

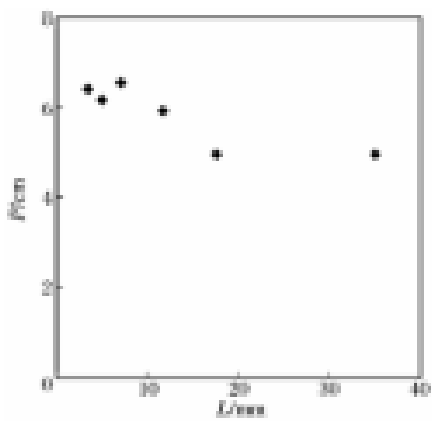

Figure 11: DOP vs. segment length for different segmented rods.

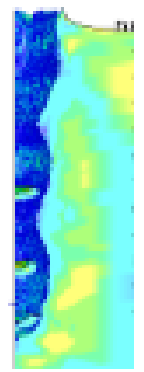

(d)

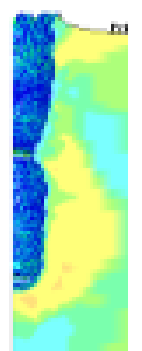

(e)

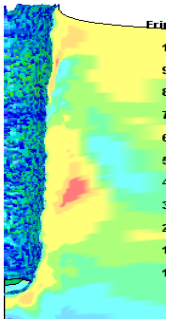

(f)

Figure 12: Von Mise stress distribution in targets for different segmented rods:
(a) $\mathrm{L}=3.5 \mathrm{~mm}, \quad t=116 \mu \mathrm{s}$;
(b) $\mathrm{L}=5.0 \mathrm{~mm}, \quad t=96.6 \mu \mathrm{s}$;
(c) $\mathrm{L}=7 \mathrm{~mm}$, $t=88.2 \mu \mathrm{s}$;
(d) $\mathrm{L}=11.7 \mathrm{~mm}, \quad t=70.2 \mu \mathrm{s}$;
(e) $\mathrm{L}=17.5 \mathrm{~mm}$
$t=55.8 \mu \mathrm{s}$;

(f) $\mathrm{L}=35 \mathrm{~mm}, t=53.6 \mu \mathrm{s}$. 
$\mathrm{L}=3.5 \mathrm{~mm}, 5 \mathrm{~mm}$ and $7 \mathrm{~mm}$, have better penetration performance. When the segment length is larger than $11.7 \mathrm{~mm}$, DOP decreases to that of long rod. There exists an optimized range of segment aspect ratio when we design the segmentrod, and here corresponds to the segment length of $3.5-7 \mathrm{~mm}$.

Fig. 13 shows the pressure-time curves at the contact surfaces between the target and the segmented rods with different segment length. Correspondingly, Fig. 14 shows the penetration velocities of segmented rods and the segmentedrod tail velocities. Regarding the segment length $\mathrm{L}=3.5 \mathrm{~mm}$ and $7 \mathrm{~mm}$, the rodtarget interface pressure decreases monotonously between $10 \mathrm{GPa}$ to $18 \mathrm{GPa}$, and it indicates the major contribution to ideal segment-rod penetration is Phase III rather than Phase II of quasi-steady penetration. Regarding the segment length $\mathrm{L}=11.7 \mathrm{~mm}$ and $17.5 \mathrm{~mm}$, the rod-target interface pressure almost varies in a narrow range from $15 \mathrm{GPa}$ to $18 \mathrm{GPa}$, and its major contribution to penetration is the Phase II of quasi-steady penetration, which is really similar to the long rod penetration. Obviously, the velocity distribution of the rod head and the rod tail in Fig. 14 further supports this conclusion.
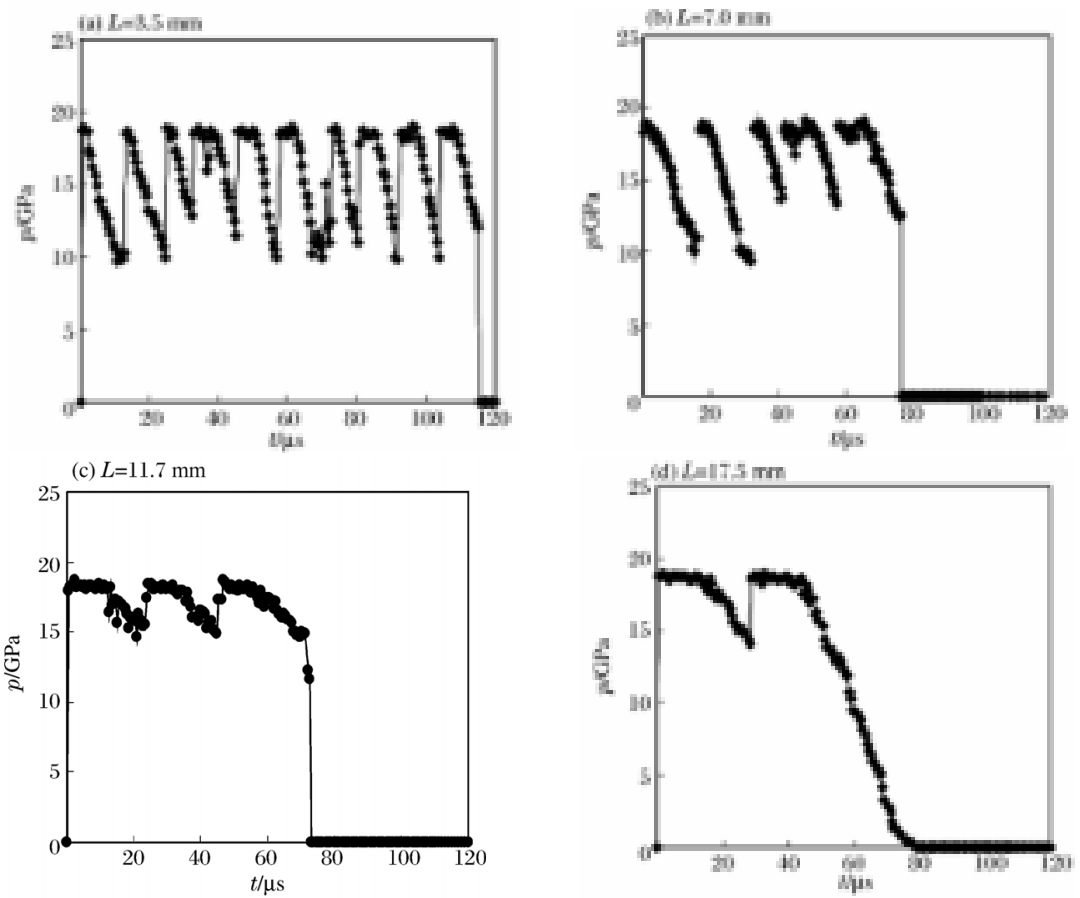

Figure 13: Pressure vs. time at contact surfaces between segmented rods and target. 

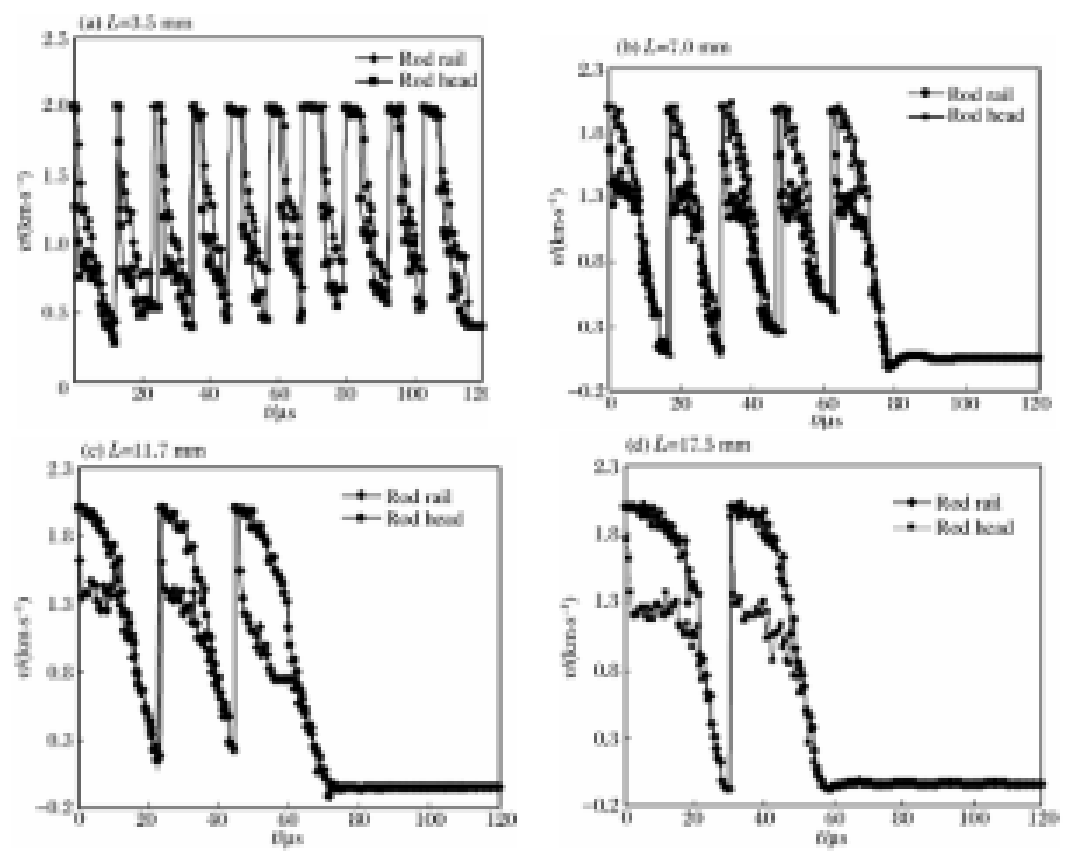

Figure 14: The segmented-rod velocities and segmented-rod tail velocities.

\section{Penetration of ideal segment-rod with different gap distance}

In this section, we simulated the penetration of ideal segment-rod with different gap distance at the initial velocity of $v_{0}=2.0 \mathrm{~km} / \mathrm{s}$. The segment length is $\mathrm{L}=7 \mathrm{~mm}$ but the gap distance are $S=0,3.5 \mathrm{~mm}, 5 \mathrm{~mm}, 7 \mathrm{~mm}, 10.5 \mathrm{~mm}, 14 \mathrm{~mm}$ and $21 \mathrm{~mm}$, respectively. Especially, $\mathrm{S}=0$ stands for the long rod penetration.

Fig. 15 shows the relation between DOP and time for the segmented rods with different gap distance, and Fig. 16 shows the variation of DOP with the gap

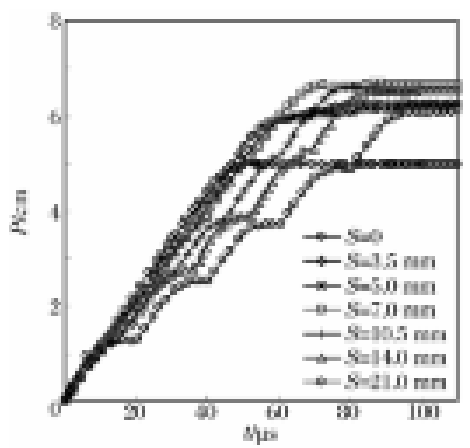

Figure 15: DOP vs. time for segmented rods with different gap distances.

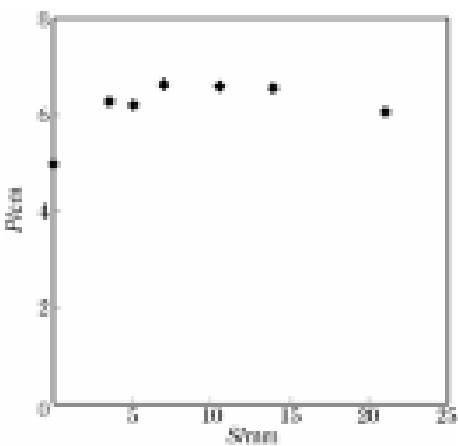

Figure 16: DOP vs. the gap distance for different segmented rods. 
distance. It shows that the penetration performance of segmented rod is quite better in the cases of relative large gap distance, e.g., $\mathrm{S}=7 \mathrm{~mm}, 10.5 \mathrm{~mm}$ and $14 \mathrm{~mm}$. However, when the gap distance is less than $5 \mathrm{~mm}$ or larger than $21 \mathrm{~mm}$, the DOP decreases but still is larger than that of long rod. It demonstrates that there is an optimized range of the gap distance regarding the segment-rod, and here corresponds to the gap distance of $7-14 \mathrm{~mm}$. Also, Fig. 17 shows the Von Mise stress distribution in targets and it confirms the above analysis.

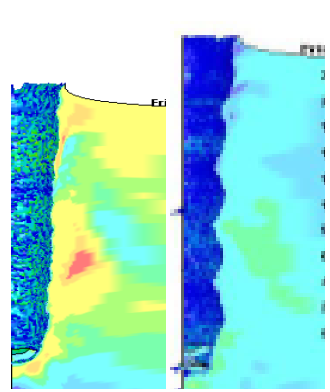

(a)

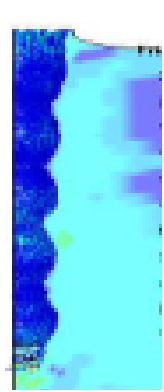

(c)

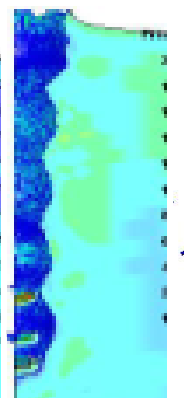

(d)

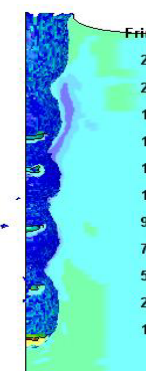

(e)

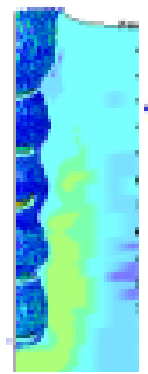

(f)

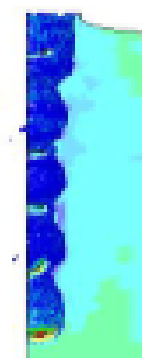

$(\mathrm{g})$

Figure 17: Von Mise stress distribution in targets penetrated by segmented rods with different gap spacings: (a) $\mathrm{S}=0 \mathrm{~mm}, t=53.6 \mu \mathrm{s}$; (b) $\mathrm{S}=3.5 \mathrm{~mm}, t=84.6 \mu \mathrm{s}$; (c) $\mathrm{S}=5.0 \mathrm{~mm}, t=98.4 \mu \mathrm{s}$; (d) $\mathrm{S}=7.0 \mathrm{~mm}$, $t=72.6 \mu \mathrm{s} ; \quad$ (e) $\mathrm{S}=10.5 \mathrm{~mm}, \quad t=78.5 \mu \mathrm{s} ; \quad$ (f) $\mathrm{S}=14 \mathrm{~mm}, \quad t=88.2 \mu \mathrm{s}$; (g) $\mathrm{S}=21 \mathrm{~mm}, t=96.6 \mu \mathrm{s}$.

Fig. 18 shows the pressure-time curves at the contact surfaces between the target and the segmented rods with different gap distance $(\mathrm{S}=3.5 \mathrm{~mm}, 7 \mathrm{~mm}$, $14 \mathrm{~mm}$ and $21 \mathrm{~mm})$. In the case of small gap distance $(\mathrm{S}=3.5 \mathrm{~mm})$, the rod-target interface pressure almost keeps a constant value in a narrow range from $15 \mathrm{GPa}$ to $18 \mathrm{GPa}$. When the gap distance is large, e.g., $\mathrm{S}=7 \mathrm{~mm}-21 \mathrm{~mm}$, it obviously affect the rod-target interface pressure and the pressure decreases monotonously from $18 \mathrm{GPa}$ to $10 \mathrm{GPa}$ for each segment. Correspondingly, Fig. 19 shows the penetration velocities of segmented rods and the segmented-rod tail velocities. In the cases of large gap distance (e.g., $\mathrm{S}=14 \mathrm{~mm}$ and $21 \mathrm{~mm}$ ), each segment may complete the penetration and the final velocity of each segment is zero. When the total number of segments is confined, if the gap distance is assumed to be larger than a certain value, for example, $\mathrm{S}>3.5 \mathrm{~mm}$ in this scenario, it has little influence on the DOP and the DOP is distinctly larger than that of long rod penetration. 

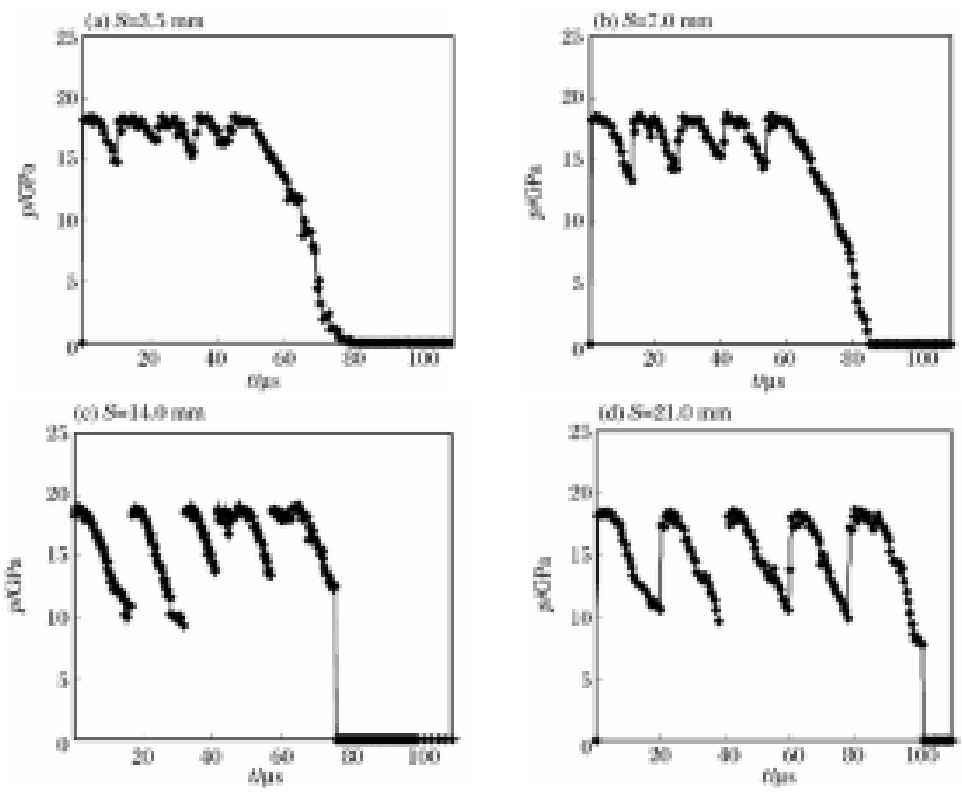

Figure 18: Pressure-time curves at the contact surfaces between segmented rods and targets penetrated by segmented rods with different gap distances.
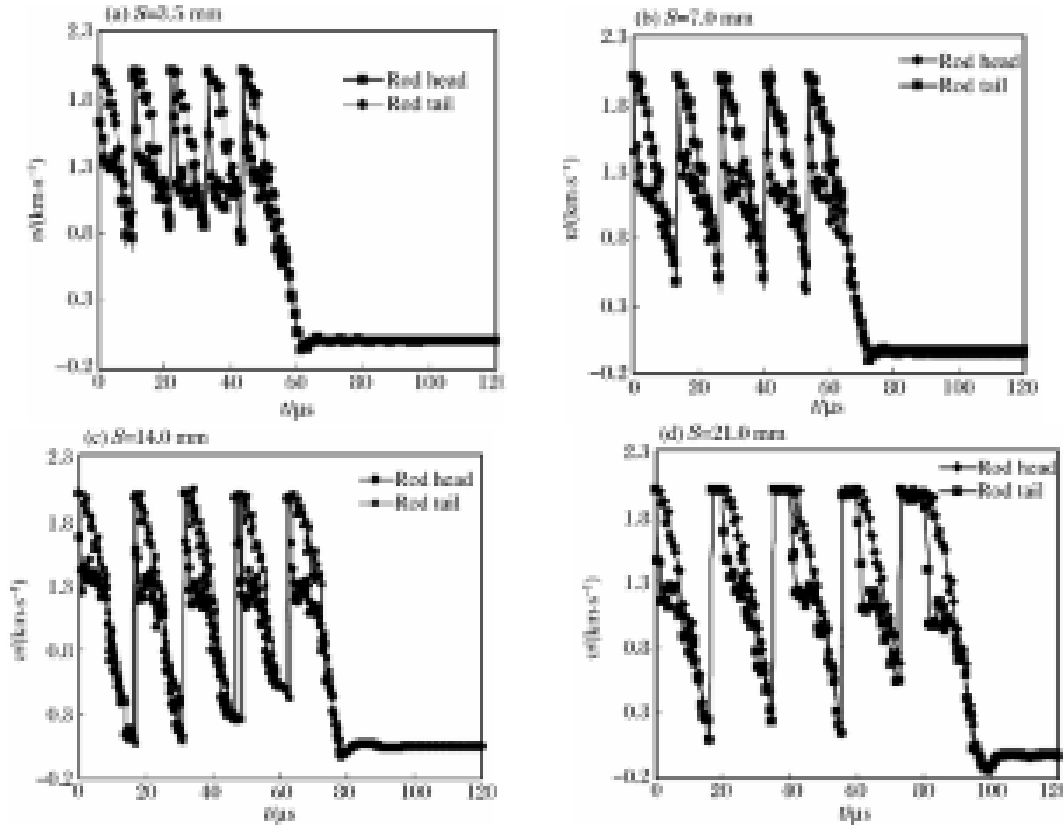

Figure 19: Penetration velocities of segmented rods and the segmented-rod tail velocities regarding different gap distances. 


\section{Conclusions}

The penetration behaviors of long-rod and ideal segment-rod with different segment aspect ratio and gap distance are numerically simulated. We achieve the following main views: 1). It indicates that the major contribution to the DOP of segment-rod is Phase III, i.e., crater initially expanding, but not the Phase II quasi-steady penetration, which is dominant in penetration of long-rod. 2). The aspect ratio and gap distance of segment do not affect DOP monotonically increasing or decreasing, instead there exists an optimal parameter region. It may give helpful suggestions for the design of armor piercing segment-projectiles.

\section{Acknowledgement}

This work is supported by the National Outstanding Young Scientists Foundation of China (Grant No. 11225213).

\section{References}

[1] Alekseevskii V.P., Penetration of a rod into target at high velocity. Combus Explos Shock Waves, 2, pp. 63-66, 1966.

[2] Tate A., A theory of the deceleration of long rods after impact. $J$ Mech Phys Solids, 15, pp. 387-399, 1967.

[3] Orphal D.L., Miller C.W., Penetration performance of non-ideal segmented rods. Int J Impact Engng, 11, pp. 457-461, 1991.

[4] Sorensen B.R., Kimsey K.D., Silsby G.F., et al., High velocity penetration of steel targets. Int J Impact Engng, 11, pp. 107-109, 1991.

[5] Cuadros J.H., Monolithic and segmented projectile penetration experiments in the 2 to 4 kilometers per second impact velocity regime. Int J Impact Engng, 10, pp. 147-157, 1991.

[6] Wang X.M., Zhao G.Z., Shen P.H., High velocity impact of segmented rods with an aluminum carrier tube. Int J Impact Engng, 17, pp. 915-923, 1995.

[7] Chen X.W., Lang L., He L.L., Numerical Simulations on Long-Rod and Segmented-Rod Penetrating into Steel Target, 8th International Symposium on Impact Engineering (ISIE2013), September 2-6, 2013, Osaka, Japan. Or: Explosion and Shock Waves(in Chinese), 31(2), pp. 127$135,2011$.

[8] Chen X.W., Lang L., Numerical simulation for penetration of long rod to steel target. ACTA ARMAMENTARII (in Chinese), 32(S2), pp. 5-11, 2011.

[9] Lang L., Chen X.W., Lei J.S., Numerical simulations on long rods and segmented rods penetrating into steel targets. Explosion and Shock Waves(in Chinese), 31(2), pp. 127-135, 2011.

[10] Chen X.W., Lang L., Effects of segment length and gap spacing on segmented rods penetrating into steel target. Explosion and Shock Waves(in Chinese), 33S, pp. 1-7, 2013. 
[11] Johnson G.R., Cook W.H., A constitutive model and data for metals subjected to large strains, high strain rates and high temperature. Proc 7 th Int Symp Ballistics, pp. 541-547, 1983.

[12] Lan B., Wen H.M., Numerical simulation and analysis of the penetration of Tungsten-alloy long rod into semi-infinite armour steel targets. $J$ High Pressure Physics (in Chinese), 22(3), pp. 245-252, 2008.

[13] Orphal D.L. Phase three penetration. Int J Impact Engng, 20, pp. 601-616, 1997. 